\title{
Timing of Repair or Reconstruction after Knee Dislocation
}

\author{
Gregory C. Fanelli, MD ${ }^{1}$ \\ ${ }^{1}$ Department of Sports Medicine and Orthopaedics, Geisinger Health \\ System, Danville, Pennsylvania \\ J Knee Surg 2020;33:335-338.
}

\author{
Address for correspondence Gregory C. Fanelli, MD, Department of \\ Sports Medicine and Orthopaedics, Geisinger Health System, \\ 16 Woodbine Lane, Danville, PA 17822-5212 \\ (e-mail: gregorycfanelli@gmail.com).
}

\author{
Abstract \\ Keywords \\ - multisystem injury \\ complex \\ - articular surface \\ - alignment \\ - instability pattern \\ - vascular assessment \\ - surgical timing \\ - staged \\ reconstruction \\ - external fixation
}

The multiple ligament injured knee (knee dislocation) is, often times, part of a multisystem injury complex that can include not only injuries to knee ligaments but also to blood vessels, skin, nerves, bones (fractures), head injuries, and other organ system trauma. These additional injuries can affect surgical timing for knee ligament reconstruction and also affect the results of the treatment. This article will present the author's approach and experience in the initial assessment and treatment of the acute multiple ligament injured (dislocated) knee, and also present considerations in the treatment of chronic multiple ligament injured knee.

\section{Surgical Timing in the Acute Multiple Ligament Injured (Dislocated) Knee}

Surgical timing in the multiple ligament injured (dislocated) knee is influenced by the vascular status of the injured extremity, the medial and lateral side injury severities, the postreduction stability, and additional surgical timing modifiers or considerations. Delayed reconstruction of 2 to 3 weeks may result in less postoperative motion loss. My ideal surgical approach is a single-stage procedure performed within 2 to 4 weeks of the patient's initial injury. Ideal surgical timing is not always possible. Surgical timing modifiers and considerations in the acute multiple ligament injured (dislocated) knee that may cause surgery to be performed earlier or later than what the surgeon considers ideal include vascular injuries, irreducible dislocations, open injuries, skin condition, extensor mechanism disruption, reduction stability, fractures or articular surface injuries, head trauma, and visceral injuries. The takehome message is that ideal surgical timing is not always possible, staged surgical reconstruction may be required, and to use external fixation when acute stabilization is required until the definitive treatment can be performed. When staged reconstruction is employed, the knee must be protected between stages; therefore, the initial stage reconstruction is not compromised with overaggressive physical activity. ${ }^{1-5}$

\section{Fractures}

Articular surface fractures in the multiple ligament injured (dislocated) knee must be anatomically reduced and internal fixation achieved before the knee ligament instability pattern can be determined since the intact femur or tibia will fall into the fracture, and potentially hinder an accurate knee ligament injury diagnosis. Tibial plateau depression fractures that meet nonsurgical criteria with intact knee ligaments should be anatomically reduced and secured since the tendency will be for the femoral condyle to fall into the fracture site, perpetuate the instability, and compromise knee ligament repair or reconstruction. Fracture reduction and fixation must be achieved to determine instability patterns, and intra-articular fractures must be reduced and stabilized to protect future ligament reconstructions. received

September 5, 2019

accepted

September 17, 2019

published online

November 4, 2019
Copyright $\odot 2020$ by Thieme Medical Publishers, Inc., 333 Seventh Avenue, New York, NY 10001, USA. Tel: +1(212) 760-0888.
DOI https://doi.org/ 10.1055/s-0039-1700573. ISSN 1538-8506. 


\section{Instability Patterns}

Identifying the multiple planes of instability in multiple knee ligament injury patients is essential for successful treatment of these injuries. The posterior cruciate ligament (PCL) and anterior cruciate ligament (ACL) disruptions will lead to increased posterior and anterior laxities at 90 and 30 degrees of knee flexion. Recognition and correction of the medial and lateral side instabilities are the key to successful PCL and ACL surgeries.

There are three different types of instability patterns that I have observed in medial and lateral side knee injuries. $^{6-8}$ These are type $\mathrm{A}$ (axial rotation instability only), type B (axial rotation instability combined with varus and/or valgus laxity with a soft end point), and type $C$ (axial rotation instability combined with varus and/or valgus laxity with little or no end point). The axial rotation instability (type A) medial or lateral side is most frequently overlooked. It is also critical to understand that combined medial and lateral side instabilities of different types occur with bicruciate and unicruciate multiple ligament knee injuries. Examples include PCL, ACL, lateral side type $\mathrm{C}$, and medial side type $\mathrm{A}$ or PCL, medial side type $\mathrm{B}$, and lateral side type $A$ instability patterns.

A combination of careful clinical examination, radiographs, and magnetic resonance imaging studies aide in determining the correct diagnosis of multiple ligament knee injuries. Knee examination under anesthesia combined with fluoroscopy, stress radiography, and diagnostic arthroscopy also contribute to accurately diagnose the multiple planes of instability. ${ }^{9-11}$ Correct diagnosis with recognition and correction of the medial and lateral side instabilities is the key to successful PCL and ACL surgery.

\section{Vascular Assessment}

Arterial injury may occur with acute multiple ligament knee injuries and knee dislocations. These arterial injuries may present as complete arterial disruptions or occlusions, or as intimal flap tears that may cause delayed arterial occlusion. Bicruciate knee ligament injuries have the same incidence as tibiofemoral dislocations that present unreduced. Initial vascular evaluation of the acute multiple ligament injured dislocated knee includes physical examination for symmetry of pulses between the injured and noninjured lower extremities, and ankle brachial index (ABI) measurements. Abnormal or asymmetrical pulses or an ABI of less than 0.9 indicates the need for vascular consultation, advanced arterial imaging studies, and potential vascular surgical intervention. ${ }^{12-17}$ Deep venous thrombosis (DVT) can occur with multiple ligament (dislocated) knee injuries in both the acute and chronic settings, and evaluation for DVT may be considered.

Up to $12 \%$ of popliteal arteries may have abnormal branching patterns, and this may be important for planning surgical reconstruction in the multiple ligament injured knee. ${ }^{17-21}$ In addition, a certain number of multiple knee ligament injury patients will have had arterial repair or reconstruction. It is important to know about potential abnormal branching patterns of the popliteal artery, and the location of arterial reconstructions, to avoid injury to these structures during multiple knee ligament reconstruction surgical procedures.

Arterial and venous assessments in the acute (and chronic) multiple ligament injured knee are important to evaluate for acute arterial injuries, DVT, abnormal popliteal artery branching patterns, and the location of arterial repair and reconstructions in the multiple ligament injured knee.

\section{Peroneal Nerve Injury}

Peroneal nerve injuries may occur with multiple knee ligament injuries and knee dislocations, and may influence the outcomes of multiple ligament knee reconstruction surgery. Treatment options for the nerve injury include nerve repair, nerve grafting, and direct nerve transfer. Our preferred treatment includes peroneal nerve decompression at the time of the initial knee ligament surgery. When the nerve is in continuity, serial electromyograms are obtained. When no nerve recovery is demonstrated, posterior tibial tendon transfer is performed. ${ }^{22}$ It is important to avoid heel cord contracture and equinus deformity at the foot and ankle since this will cause the knee to hyperextend during the stance phase of gait, and may compromise knee ligament reconstruction.

\section{External Fixation}

External fixation is a useful tool in the management of the multiple ligament injured knee. Preoperative indications for the use of spanning external fixation include open dislocations, vascular repair, and inability to maintain reduction. ${ }^{23}$ The advantages of using spanning external fixation include skin assessment, compartment pressure observation, and monitoring the neurovascular status of the affected limb. Preoperative use of external fixation compared with brace immobilization may lead to less terminal flexion postoperatively; however, this may be more dependent on injury severity of the involved extremity than the use of the spanning external fixation device. ${ }^{4}$ Postoperative protection of multiple knee ligament reconstructions in a hinged external fixation device may lead to more favorable static stability than postoperative brace immobilization. ${ }^{24}$ The use of spanning external fixation in the treatment of multiple ligament injured knee preoperatively and postoperatively is based on the individual case. If I can control the knee in a brace, I use a brace. If I cannot control the knee in a brace, I use an external fixation device. Postapplication Xrays are used to confirm initial reduction and that reduction is maintained. Occasionally, I have used a spanning external fixator for treatment of the multiple ligament injured knee in patients who are not surgical candidates. The use of spanning external fixation in treatment of the multiple ligament injured knee preoperatively and postoperatively is based on the individual case. 


\section{Considerations in the Chronic Multiple Ligament Injured Knee}

\section{Alignment}

Femur or tibia fractures requiring reduction and fixation may require that multiple ligament reconstruction be performed after fracture healing has occurred. When varus or valgus alignment with resultant varus or valgus thrust during the stance phase of gait is present after fracture healing, consideration should be given to fracture fixation hardware removal (stage 1) followed by corrective osteotomy (stage 2) to restore normal alignment and gait pattern, followed by knee ligament reconstruction (stage 3 ) when the osteotomy has healed and osteotomy hardware has been removed if necessary. A normal gait pattern with the absence of a varus or valgus thrust will improve the chance for successful knee ligament reconstruction. Lower extremity malalignment with varus or valgus thrust during the stance phase of gait should be corrected with osteotomy prior to ligament reconstruction to maximize the chance for successful knee ligament reconstruction results.

\section{Conclusion}

The multiple ligament injured knee (knee dislocation) is, often times, part of a multisystem injury complex that can include not only injuries to knee ligaments but also to blood vessels, skin, nerves, bones (fractures), head injuries, and other organ system trauma. These additional injuries can affect surgical timing for knee ligament reconstruction and also affect the results of treatment.

Surgical timing in the multiple ligament injured (dislocated) knee is influenced by the vascular status of the injured extremity, the medial and lateral side injury severities, the postreduction stability, and additional surgical timing modifiers or considerations. Ideal surgical timing is not always possible. Staged surgical reconstruction may be required, and external fixation may be used when acute stabilization is required until the definitive treatment can be performed.

The use of spanning external fixation in the treatment of multiple ligament injured knee preoperatively and postoperatively is based on the individual case. If I can control the knee in a brace, I use a brace. If I cannot control the knee in a brace, I use an external fixation device. Postapplication X-rays are used to confirm initial reduction and that reduction is maintained.

Fracture reduction and fixation must be achieved to determine instability patterns, and intra-articular fractures must be reduced and stabilized to protect future ligament reconstructions.

Arterial and venous assessments in the acute (and chronic) multiple ligament injured knee are important to evaluate for acute arterial injuries, DVT, abnormal popliteal artery branching patterns, and the location of arterial repair and reconstructions in the multiple ligament injured knee.

Peroneal nerve injuries may occur in the multiple ligament injured (dislocated) knee and can be treated by peroneal nerve decompression, nerve repair, nerve grafting, direct nerve transfer, and tendon transfer. It is important to avoid heel cord contracture and equinus deformity at the foot and ankle since this will cause the knee to hyperextend during the stance phase of gait, and may compromise knee ligament reconstruction.

In chronic multiple ligament knee injuries, lower extremity malalignment with varus or valgus thrust during the stance phase of gait should be corrected with osteotomy prior to ligament reconstruction to maximize the chance for successful knee ligament reconstruction results. Correct diagnosis with recognition and correction of the medial and lateral side instability is the key to successful PCL and ACL surgeries.

\section{Conflict of Interest}

None declared.

\section{References}

1 Fanelli GC, Orcutt DR, Edson CJ. The multiple-ligament injured knee: evaluation, treatment, and results. Arthroscopy 2005;21 (04):471-486

2 Mook WR, Miller MD, Diduch DR, Hertel J, Boachie-Adjei Y, Hart JM. Multiple-ligament knee injuries: a systematic review of the timing of operative intervention and postoperative rehabilitation. J Bone Joint Surg Am 2009;91(12):2946-2957

3 Levy BA, Dajani KA, Whelan DB, et al. Decision making in the multiligament-injured knee: an evidence-based systematic review. Arthroscopy 2009;25(04):430-438

4 Levy BA, Fanelli GC, Whelan DB, et al; Knee Dislocation Study Group. Controversies in the treatment of knee dislocations and multiligament reconstruction. J Am Acad Orthop Surg 2009;17 (04):197-206

5 Fanelli GC, Stannard JP, Stuart MJ, et al. Management of complex knee ligament injuries. J Bone Joint Surg Am 2010;92(12):2235-2246

6 Fanelli GC, Feldman DD. Management of combined anterior cruciate ligament/posterior cruciate ligament/posterolateral complex injuries of the knee. Oper Tech Sports Med 1999;7(03):143-149

7 Fanelli GC, Harris JD. Late MCL (medial collateral ligament) reconstruction. Tech Knee Surg 2007;6(02):99-105

8 Fanelli GC, Harris JD. Surgical treatment of acute medial collateral ligament and posteromedial corner injuries of the knee. Sports Med Arthrosc Rev 2006;14(02):78-83

9 Fanelli GC, Giannotti BF, Edson CJ. The posterior cruciate ligament arthroscopic evaluation and treatment. Arthroscopy 1994;10 (06):673-688

10 Fanelli GC, ed. Arthroscopic evaluation of the PCL. In: Posterior Cruciate Ligament Injuries. A Practical Guide to Management. New York: Springer-Verlag; 2001:95-105

11 LaPrade RF. Arthroscopic evaluation of the lateral compartment of knees with grade 3 posterolateral knee complex injuries. Am J Sports Med 1997;25(05):596-602

12 Green NE, Allen BL. Vascular injuries associated with dislocation of the knee. J Bone Joint Surg Am 1977;59(02):236-239

13 Welling RE, Kakkasseril J, Cranley JJ. Complete dislocations of the knee with popliteal vascular injury. J Trauma 1981;21(06):450-453

14 Wascher DC, Dvirnak PC, DeCoster TA. Knee dislocation: initial assessment and implications for treatment. J Orthop Trauma 1997;11(07):525-529

15 Kennedy JC. Complete dislocations of the knee joint. J Bone Joint Surg Am 1963;45:889-904

16 Mills WJ, Barei DP, McNair P. The value of the ankle-brachial index for diagnosing arterial injury after knee dislocation: a prospective study. J Trauma 2004;56(06):1261-1265

17 Wascher DC. High-velocity knee dislocation with vascular injury. Treatment principles. Clin Sports Med 2000;19(03):457-477 
18 Mavili E, Dönmez H, Kahriman G, Özaşlamacı A, Özcan N, Taşdemir K. Popliteal artery branching patterns detected by digital subtraction angiography. Diagn Interv Radiol 2011;17 (01):80-83

19 Butt U, Samuel R, Sahu A, Butt IS, Johnson DS, Turner PG. Arterial injury in total knee arthroplasty. J Arthroplasty 2010;25(08): 1311-1318

20 Kim D, Orron DE, Skillman JJ. Surgical significance of popliteal arterial variants. A unified angiographic classification. Ann Surg 1989;210(06):776-781

21 Keser S, Savranlar A, Bayar A, Ulukent SC, Ozer T, Tuncay I. Anatomic localization of the popliteal artery at the level of the knee joint: a magnetic resonance imaging study. Arthroscopy 2006;22(06):656-659

22 Alejandro SF, Maloney PJ, Cush GJ. Tendon transfers for peroneal nerve injuries in the multiple ligament injured knee. In: Fanelli GC, ed. The Multiple Ligament Injured Knee. A Practical Guide to Management, 3rd ed. Switzerland: Springer Nature Switzerland AG; 2019:357-367

23 Stuart MJ. Evaluation and treatment principles of knee dislocations. Oper Tech Sports Med 2001;9(02):91-95

24 Stannard JP, Nuelle CW, McGwin G, Volgas DA. Hinged external fixation in the treatment of knee dislocations: a prospective randomized study. J Bone Joint Surg Am 2014;96(03):184-191 